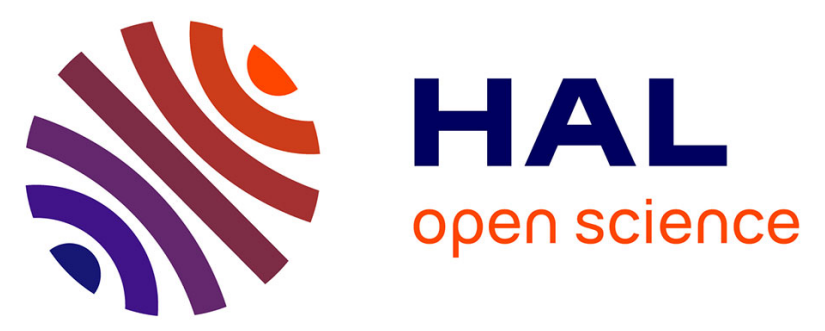

\title{
Two-Photon Absorbing AIEgens: Influence of Stereoconfiguration on Their Crystallinity and Spectroscopic Properties and Applications in Bioimaging
}

Jean Rouillon, Jan Blahut, Marion Jean, Muriel Albalat, Nicolas Vanthuyne, Anne Lesage, Lamiaa Ali, Kamel Hadj-Kaddour, Mélanie Onofre, Magali Gary-Bobo, et al.

\section{To cite this version:}

Jean Rouillon, Jan Blahut, Marion Jean, Muriel Albalat, Nicolas Vanthuyne, et al.. Two-Photon Absorbing AIEgens: Influence of Stereoconfiguration on Their Crystallinity and Spectroscopic Properties and Applications in Bioimaging. ACS Applied Materials \& Interfaces, 2020, 10.1021/acsami.0c15810 . hal-03044490

\author{
HAL Id: hal-03044490 \\ https://hal.science/hal-03044490
}

Submitted on 7 Dec 2020

HAL is a multi-disciplinary open access archive for the deposit and dissemination of scientific research documents, whether they are published or not. The documents may come from teaching and research institutions in France or abroad, or from public or private research centers.
L'archive ouverte pluridisciplinaire HAL, est destinée au dépôt et à la diffusion de documents scientifiques de niveau recherche, publiés ou non, émanant des établissements d'enseignement et de recherche français ou étrangers, des laboratoires publics ou privés. 


\title{
Two-photon absorbing AIEgens: influence of stereoconfiguration on their crystallinity and spectroscopic properties, applications in bioimaging
}

\author{
Jean Rouillon†, Jan Blahut ${ }^{\ddagger}$, Marion Jean§, Muriel Albalat§, Nicolas Vanthuyne§, Anne Lesage ${ }^{\ddagger}$,

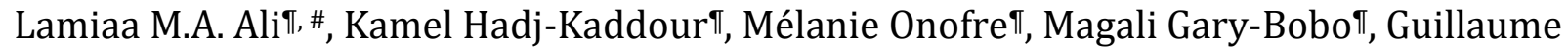 \\ Micouin ${ }^{\dagger}$, Akos Banyasz $^{\dagger}$, Tangui Le Bahers ${ }^{\dagger}$, Chantal Andraud $^{\dagger}$ and Cyrille Monnereau ${ }^{\dagger *}$ \\ †Univ. Lyon, ENS Lyon, CNRS, Université Lyon 1, Laboratoire de Chimie, UMR 5182, 46 Allée d’Italie, 69364 Lyon, \\ France. \\ §Aix-Marseille Univ, CNRS, Centrale Marseille, iSm2, Marseille, France. \\ ‡ Univ Lyon, ENS Lyon, Université Lyon 1, CNRS, High-Field NMR Center of Lyon, FRE 2034, F-69100 VILLEURBANNE, \\ France. \\ IIBMM, Univ Montpellier, CNRS, ENSCM, Montpellier, France. \\ \# Department of Biochemistry, Medical Research Institute, University of Alexandria, Alexandria, Egypt.
}

KEYWORDS: Aggregation Induced Emission, Two-Photon Absorption, stereoconfiguration, bioimaging, crystallinity

\begin{abstract}
This paper aims at designing chromophores with high aggregation induced emission (AIE) properties for twophoton fluorescence microscopy (2PFM), which is one of the best suited types of microscopy for the imaging of living organism or thick biological tissues. Tetraphenylethylene (TPE) derivatives are common building blocks in the design chromophores with efficient AIE properties. Therefore, in this study, extended TPE AIEgens specifically optimized for twophoton absorption (2PA) are synthetized and the resulting (E/Z) isomers are separated using chromatography on chiral supports. Comparative characterization of the AIE properties is performed on the pure (Z) and (E) isomers and the mixture, allowing us, in combination with powder X-ray diffraction and solid-state NMR to document a profound impact of crystallinity on solid state fluorescence properties. In particular, we show that stereopure AIEgens form aggregates of superior crystallinity, which in turn exhibit a higher fluorescence quantum yield compared to diastereoisomers mixtures. Preparation of stereopure organic nanoparticles affords very bright fluorescent contrast agents, which interest for cellular and intravital two-photon microscopy is illustrated on human breast cancer cell line and on zebrafish embryos.
\end{abstract}

\section{INTRODUCTION}

"Colour is all. When colour is right, form is right". These words from Marc Chagall, a franco-russian painter, can be applied also to the chemistry of fluorophores. Indeed, characteristics of an organic fluorophore are strongly dependent not only on its structure (length of $\pi$-conjugated system, electronic nature of groups...) but sometimes even more critically on its physical state (solid, solution, suspension...). Influence of chromophore's physical state on luminescence properties has been widely studied in recent years, due to the applicative interest of solid state emitters in such various fields as lighting (OLED), ${ }^{1-3}$ display, and imaging (biosensing, bioimaging...). . $^{4,5}$ Unfortunately, for most usual organic chromophores, applicative interests in these domains are affected by the so-called aggregationcaused quenching (ACQ) of fluorescence. In this context, molecules featuring AIE properties have been widely studied as a possible remediation to this issue. Although examples of fluorescence enhancement in rigidified chromophores were depicted in the literature since the early-twentieth century, ${ }^{6}$ the series of works started by Ben Zhong Tang et al in $2001^{7}$ largely contributed not only in popularizing the topic but also in bringing a rational basis for the design of AIEgens. As a common feature for most AIEgens, quenching of fluorescence in solution is provided by multiple non-radiative relaxation (vibrational relaxation, isomerisation....). ${ }^{8}$ Conversely, in the aggregated state, a restriction of intramolecular motion in the molecule suppresses most of these nonradiative channels resulting in an increase of fluorescence quantum yield. As a consequence of this model, common AIEgens are characterised by a rotor-stator structure, intramolecular rotation being in this case the nonradiative process at the origin of the AIE effect. Since Ben Zhong Tang et al initial reports, tetraphenylethylene (TPE) derivatives have probably been the most intensively explored class of compounds for this distinctive property. ${ }^{9}$ Although many reports have used TPE derivatives in the field of bioimaging and biosensing, ${ }^{5}$ examples of TPE derivatives specifically optimized in view of application in 2PFM are surprisingly scarce. ${ }^{10-12}$ 
Indeed, 2PFM presents significant advantages over classical confocal fluorescence: first, quadratic dependence of the 2PA phenomenon versus light intensity provides a strong control over the excitation volume (restricted to the focal point of the incident laser source), and thus an improved resolution and facilitated reconstruction of a 3D image; second, the use of NIR light source leads to improved penetration of light within the tissue and reduced autoluminescence. ${ }^{13,14}$

2PFM relies on the two-photon absorption (2PA) ${ }^{15}$ and thus requires the use of specifically engineered luminescent probes. More precisely, the ability of a chromophore to simultaneously absorb two-photon is quantified by the so called 2PA cross-section $\left(\sigma_{2} \mathrm{PA}\right)$. It relates primarily to the polarizability of its electron cloud, i.e. to the magnitude of the intramolecular charge transfer (ICT) along its $\pi$ conjugated backbone upon photoexcitation. ${ }^{16}$ A classical strategy to obtain chromophores with improved 2PA crosssections relies on the use of long $\pi$-conjugated structures end terminated with strong electron-donating and/or withdrawing groups. With this approach, aiming at synthesizing AIEgens with optimized $\sigma_{2 \mathrm{PA}}$, we functionalized the periphery of different TPE derivatives by a triphenylamine (TPA) electron donor group classically used in the design of 2PA molecules. ${ }^{10,17,18}$ An archetypical example of the as-designed structure, TPE-TPA, is featured in Scheme 1.

Synthetic methodologies generally used to that end being inherently non-stereospecific, a mixture of (E) and (Z) diastereoisomers is obtained. This is problematic in regard of the study of the 2PA properties of the molecule, which are particularly sensitive to the stereoconfiguration of double bonds, ${ }^{19}$ and of the packing behaviour of the compound, which is expected to drive AIE efficiency. An efficient and fast methodology is thus required to separate (Z) and (E) TPE-isomers. Several methods have been proposed in the literature for the separation of TPE diastereoisomers: adding polar functions in close vicinity of the central double bound, ${ }^{20}$ to exacerbate polarity differences in view of chromatographic separation was not applicable for our compounds; stereoselective crystallisation ${ }^{21}$ is a tedious procedure, since it is hardly compatible with the obtention of target materials on large scales.

In this article, we propose a straightforward purification procedure affording stereopure TPE-containing AIEgens with high 2PA properties, by means of liquid chromatography on chiral stationary phases. The spectroscopic properties of this family of AIEgens are fully characterized, highlighting huge discrepancies between mixed and separated isomers, and the huge benefits of stereopurity for two-photon induced AIE properties. As an illustration of the potential of our approach for bioimaging applications, preliminary one- and two-photon imaging studies are performed in vitro (on human cancer cell line) and in vivo (on zebrafish embryos).

\section{RESULTS AND DISCUSSION}

\section{Synthesis}

Synthesis of TPE-TPA is depicted in Scheme 1. For comparison 2,3-diphenyl-2-butene (DBP), 1,2-bis-(4biphenyl)-1,2-diphenylethylene (2BPE) and stilbene (S) cores were also designed (See S2 and S3 for details of each ketone). Central olefin was formed by carbon-carbon McMurry homo coupling of 4-bromobenzophenone to afford corresponding TPE-Br in good yields. Ratio of (E/Z)TPE-Br isomers of 50:50 corresponded to the usual (kinetically driven) statistic distribution of McMurry coupling 21-23 and remained unchanged throughout subsequent synthetic steps, as described below.

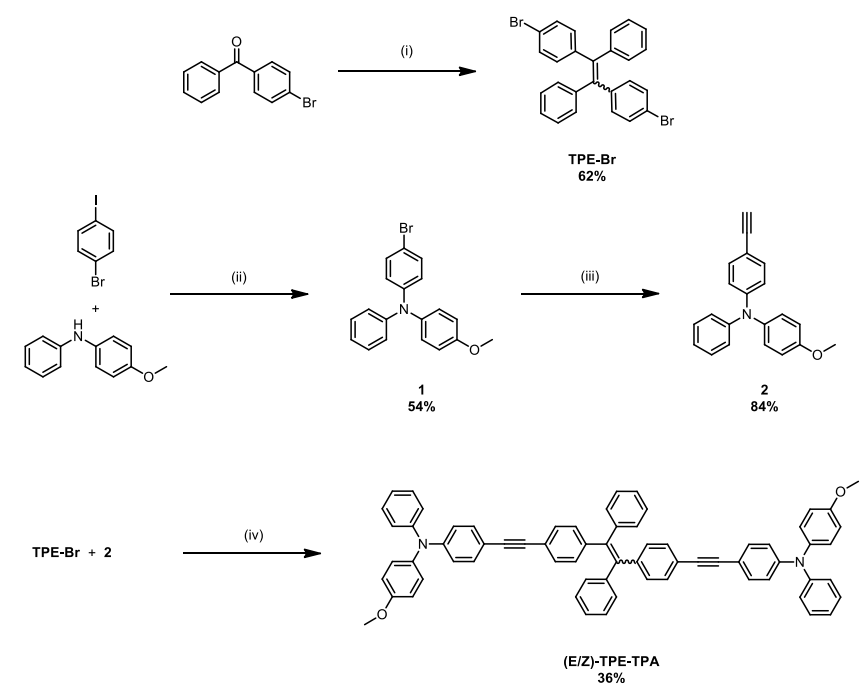

Scheme 1. Synthetic routes of (E/Z)-TPE-TPA. Reactions conditions: (i) $\mathrm{TiCl}_{4}, \mathrm{Zn}, \mathrm{THF}$, reflux; (ii) $\mathrm{Pd}(\mathrm{OAc}), \mathrm{P}\left(\mathrm{tBu}_{3}\right)$,

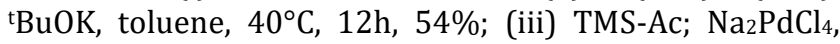
$\mathrm{P}\left({ }^{\mathrm{t}} \mathrm{Bu}\right)_{3}, \mathrm{CuI},\left({ }^{\mathrm{P} r}\right)_{2} \mathrm{NH}, 70^{\circ} \mathrm{C}, 12 \mathrm{~h}$, then $\mathrm{K}_{2} \mathrm{CO}_{3}, \mathrm{MeOH}, \mathrm{DCM}, \mathrm{rt}$, 1h, 84\% (iv) $\mathrm{Pd}(\mathrm{PhCN})_{2} \mathrm{Cl}_{2}, \mathrm{P}\left({ }^{\mathrm{t}} \mathrm{Bu}\right)_{3}, \mathrm{CuI},\left({ }^{\mathrm{i}} \mathrm{Pr}\right)_{2} \mathrm{NH}, 70^{\circ} \mathrm{C}, 12$ h, $36 \%$.

First, 4-methoxy-N-phenylaniline reacted with parabromo-iodobenzene under Buchwald-Hartwig conditions to form selectively 4-bromo-N-(4methoxyphenyl)diphenylamine (1). Then, a first Sonogashira coupling with trimethylsilylacetylene (TMSAc) was performed on compound 1: after basic deprotection, bis coupling of the 4-ethynyl-N-(4methoxyphenyl)diphenylamine (2) was achieved with all afforded mentioned dibrominated olefins. The poor reactivity of alkyne 2 was overcome by optimisation of the catalytic system : best results were achieved using the method proposed by $\mathrm{Fu}$ et al. ${ }^{24}$ with bis(benzonitrile)palladium dichloride $\left(\mathrm{Pd}(\mathrm{PhCN})_{2} \mathrm{Cl}_{2}\right)$ as a palladium source.

Differences in polarity between the two $(E)$ and $(Z)$ isomers of TPE-TPA were not sufficient for separation on column chromatography or even classical HPLC, regardless of the stationary phase or solvent mixture used. HPLC on chiral stationary phases was thus envisioned in order to perform this separation. Stereoselective interactions between isomers and polysaccharide ( $\pi$-interactions, hydrogen and 
halogen bonding, dipole-dipole, among others) lead to the formation of labile diastereomers, producing different retention within the column. ${ }^{25}$ Although normally intended for enantiomer separation, chiral chromatography has already been used in the past to improve the separation of different diastereoisomers or regioisomers. ${ }^{26-28}$ Indeed, in all cases (enantiomers, diastereoisomers, or regioisomers), the use of a chiral selector drives different retention times depending on the differences in 3D structures. Such differences in the 3D structures being particularly marked between our "V-shaped" (Z) isomer and linear (E), chiral HPLC looked like a good alternative to separate them.

In order to achieve this aim, twenty different chiral stationary phases were screened. Although no conditions were found to separate TPE-Br isomers, TPE-TPA and DPE-TPA could be baseline separated with polysaccharidebased stationary phases ${ }^{29}$, and 2BPE-TPA with the molecular chiral selector Whelk-01.30

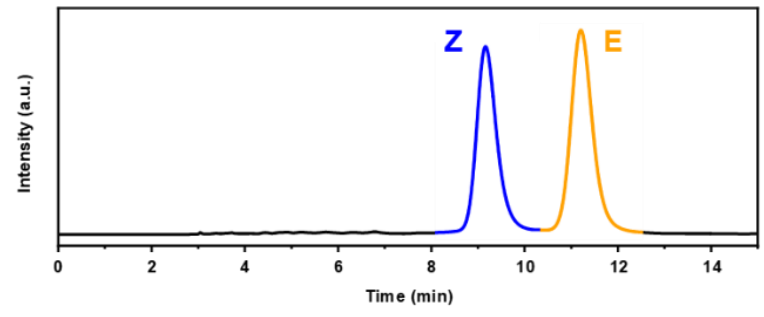

Figure 1. Chiral HPLC separation of TPE-TPA isomers.

This strategy turned out to be very efficient to obtain each isomer in hundreds of milligrams scales. In particular, separation of diastereoisomers of TPE-TPA with Chiralpak IA and hexane/ethanol, 90/10 (v/v) as eluent, was obtained with a resolution of 2.49 (Figure 1a). Attribution of the (E) and $(\mathrm{Z})$ isomers were done by comparison of their NMR spectra, on the basis of previous reports on isolated (E/Z)TPE-TPA derivatives. ${ }^{21}$ Ratio between isomers observed on chromatogram were consistent with the expected 50:50 ratio usually obtained with McMurry couplings of TPE derivatives. ${ }^{21-23}$

Similar strategy was applied for the synthesis and the separation of different diastereoisomers of 2PA-AIEgens (see S6 for 2BPE-TPA and DPB-TPA; only (E) isomer of STPA was obtained). Separated diastereoisomers, stored in the dark and at low temperature, were then studied by different spectroscopic techniques.

${ }^{1} \mathrm{H}-\mathrm{NMR}$ of both (Z) and (E) isomers of TPE-TPA gave distinctive set of chemical shifts, which superimposition well matched the spectrum obtained with the unseparated mixture, confirming the exclusive presence of these diastereoisomers in the initial mixture in a ca 50: 50 ratio (Figure S4). Overall, only little spectral differences were highlighted between both stereoisomers: in particular, methoxy group of each isomer shared an identical chemical shift (3.81 ppm) and the only significant differences were seen in the aromatics regions, where the doublet at 7.30 ppm and the multiplet at $7.11 \mathrm{ppm}$ in the (Z) isomer are respectively shifted to 7.29 and $7.13 \mathrm{ppm}$ in the (E) isomer. Although not detailed in full in this article, similar conclusions could be drawn for 2BPE-TPA and DPB-TPA (See S3 and S4).

\section{Spectroscopy}

The UV-vis absorption and photoluminescence spectra of each compound were recorded in THF (Figure 2 and Table 1), first on the diastereoisomers mixtures, then on the isolated diastereopure compounds. Although discussion in the following will be limited to the TPE-TPA series, the overall spectral pattern (absorption and emission in solution) is similar for 2BPE-TPA and DPB-TPA and interpretations of the spectroscopic behaviour are identical also for these two chromophores. All spectra are reproduced in full as supplementary material (S10)

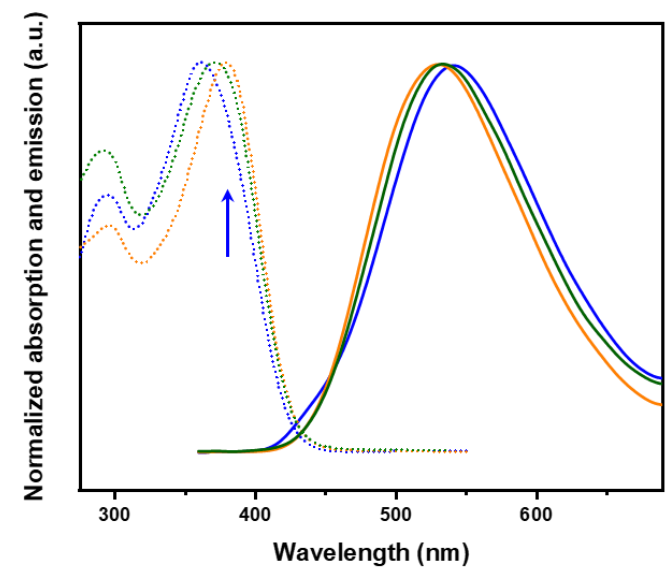

Figure 2. Absorption spectra and PL spectra of mixture of isomer (green) and separated (Z) (blue) and (E) (yellow) isomers of TPE-TPA in THF solution. Dotted lines are absorption and solid lines are emission.

Table 1. Photophysical properties of each mixture of isomers and separated (Z)-TPE-TPA and (E)-TPE-TPA in THF solution

\begin{tabular}{|c|c|c|c|}
\hline & $\begin{array}{c}\text { (E/Z)-TPE- } \\
\text { TPA }\end{array}$ & $\begin{array}{c}\text { (Z)-TPE- } \\
\text { TPA }\end{array}$ & $\begin{array}{c}\text { (E)-TPE- } \\
\text { TPA }\end{array}$ \\
\hline$\lambda_{\text {abs }}(\mathrm{nm})$ & 370 & 361 & 380 \\
\hline$\lambda_{\mathrm{em}}(\mathrm{nm})$ & 535 & 543 & 530 \\
\hline $\begin{array}{c}\text { Stokes shift } \\
\left(\mathrm{cm}^{-1}\right)\end{array}$ & 8300 & 9300 & 7400 \\
\hline$\Phi_{\mathrm{f}}\left(\mathrm{x} \mathrm{10}^{2}\right)$ & 0.4 & 1.1 & 1.8 \\
\hline
\end{tabular}

For all compounds, absorption spectrum is dominated by a broad and structureless ICT band, characteristic of extended $\pi$-conjugated chromophores. ${ }^{31}$ Emission maximum occurs with a large Stokes shift, and the associated band also presents the same broad and structureless features as the absorption, confirming the 
nature of the transition. As expected for a TPE derivative, emission intensity in solution is low.

The absorption of the isomer (Z)-TPE-TPA appears slightly blue-shifted $\left(\lambda_{\mathrm{abs}}=361 \mathrm{~nm}\right)$ compared to that of the isomer (E)-TPE-TPA $\left(\lambda_{\text {abs }}=380 \mathrm{~nm}\right)$. TD-DFT computed transitions bring a clear explanation for this trend (see Figure 3). It appears that the first absorption band observed experimentally originates from two transitions, computed at the same wavelength for both compounds (364 nm and $341 \mathrm{~nm}$ ), but differing in their relative oscillator strengths.

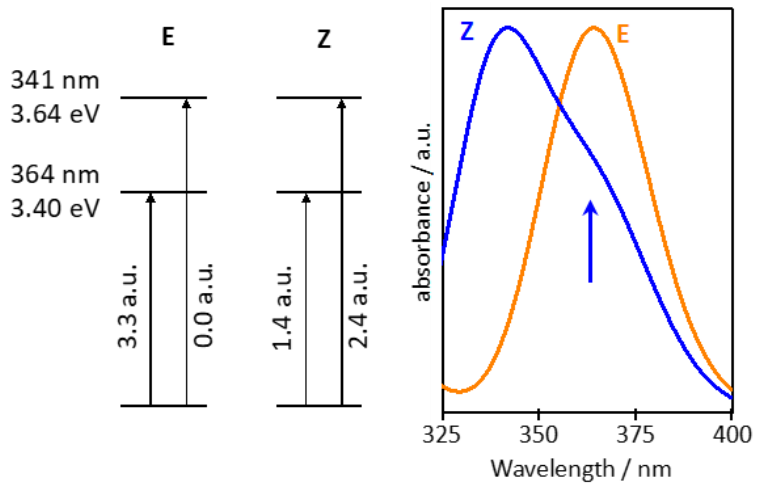

Figure 3. Computed energy levels, on the ground state geometries, for (E)-TPE-TPA and (Z)-TPE-TPA molecules along with the oscillator strength and the associated simulated absorption spectra.

This can be understood as follows: the (E) molecule can be seen as a quadrupolar donor-acceptor-donor (D-A-D) dye, a class of centrosymmetric chromophores for which the lowest absorption transition is strongly allowed, while the second one is forbidden, which clearly translates in the TDDFT results. ${ }^{31,32}$ In contrast, the (Z) compound can be seen as two dipolar D-A systems placed in an oblique-aggregate conformation. ${ }^{33}$ This organization gives rise to a Davydov splitting with an only partly allowed lowest energy transition and a more strongly allowed higher energy transition, resulting in the simulated shoulder indicated by a blue arrow on Figure 3 and clearly observed on the experimental spectra (blue arrow in Figure 2).

A major characteristic of the spectral properties of the TPETPA series are the very large Stokes shift observed between the lowest absorption and emission bands ca $7500 \mathrm{~cm}^{-1}$. This witnesses a particularly large reorganization energy accompanying internal conversion from the Frank-Condon excited state to the relaxed excited state, characteristic of large changes in the molecule geometry upon transition from the electronic ground-to-excited state. ${ }^{19}$ Again, optimized structures at the excited states using TD-DFT confirms that the reorganization process is dominated by a rotation around the dihedral angle of the central TPE moiety, going from $10^{\circ}$ in the ground state to $50^{\circ}$ in the excited state for both (Z) and (E) isomers (Figure S7). This distortion also induces a large decrease of the computed oscillator strength (and thus radiative rates) ${ }^{34}$ associated to the $\mathrm{S}_{1} \rightarrow \mathrm{S}_{0}$ transition (from 3.3 in the Frank-Condon conformation to 0.9 a.u in the relaxed system for $(\mathrm{E})$ isomer and from 1.4 to 0.8 a.u. for (Z) isomer). Although emission quenching processes in organic solution of AIEgens are known to be dominated by nonradiative process ${ }^{35}$, this trend may participate to the very weak emission efficiency reported in solution (Figure S8).

(a)

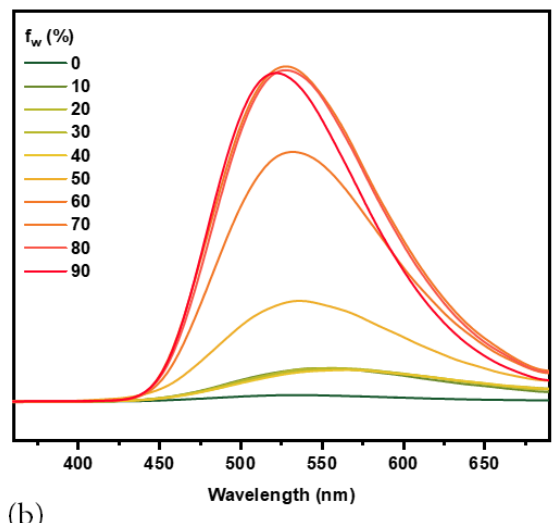

(b)

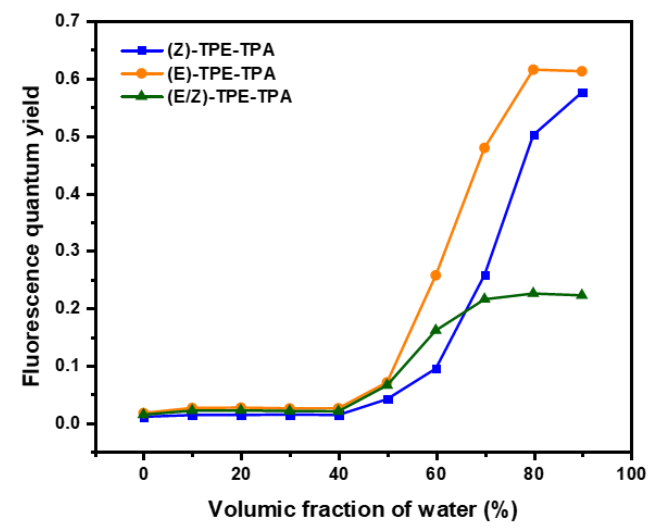

Figure 4. (a) Emission of (E/Z)-TPE-TPA in various water/THF mixtures (b) Plots of the fluorescence quantum yield of mixed isomers, pure (Z) and (E) isomers of TPE-TPA in various water/THF mixtures.

We then investigated the AIE properties of the compounds, starting with their (E/Z) mixtures, following the classical nanoprecipitation approach ${ }^{36}$ consisting in progressively increasing volume fraction of water $\left(f_{w}\right)$ in THF/water mixtures (Figures $4 \mathrm{a}$ and $4 \mathrm{~b}$ ). Concerning TPE-TPA, below $\mathrm{f}_{\mathrm{w}}$ of $50 \%$, the chromophore remains soluble in the solvent mixture and almost non-emissive (quantum yield $\Phi_{\mathrm{f}} \mathrm{Ca}$ 0.01 ). For $\mathrm{f}_{\mathrm{w}}$ higher than $50 \%$, we observed an initial blue shift of emission with a maximum of PL at $528 \mathrm{~nm}$; then, upon gradual addition of water, $\Phi_{\mathrm{f}}$ progressively increases with the $f_{w}$ to reach 0.223 at $f_{w}$ of $90 \%$, as a consequence of the formation of nanoaggregates. Comparable results were obtained for the $(\mathrm{E} / \mathrm{Z})$ mixture of the other TPE based molecule (2BPE-TPA), and, although to a much lesser extent regarding AIE efficiency, for DPB-TPA (See Fig. S10).

In contrast, $\mathbf{S}$-TPA exhibits an initial drop of luminescence efficiency with addition of water, until $\mathrm{f}_{\mathrm{w}}$ less than $50 \%$. This 
is classical for chromophores with ICT in solution, where increase in solvent polarity generally has a detrimental effect on luminescence because of enhanced non-radiative vibronic relaxation, as classically observed in literature for this type of compounds. ${ }^{37-39}$ For $\mathrm{f}_{\mathrm{w}}$ above $50 \%$, the solubility of the stilbenoïd chromophore drops, leading to precipitation of the molecule, which then exhibits relatively classical AIE properties (see Fig. S10).

Separated isomers of all compounds were then investigated individually. In the case of TPE-TPA, quantum yield in solution state remains low and virtually undistinguishable from the isomer's mixture (Figure 4b). However, as soon as the water content exceeds $50 \%$ (onset of the nanoprecipitation, as seen with the mixture), both separated isomers undergo a very different evolution in regard with the $(E / Z)$ mixture, characterized by a much improved AIE efficiency: at $\mathrm{f}_{\mathrm{w}}$ of $90 \%$, fluorescence quantum yield of 0.58 is reached for (Z)-TPE-TPA, and 0.61 for (E)TPE-TPA.

The same dependence of luminescence efficiency on stereoconfiguration and stereopurity is observed for the other variant of AIEgens investigated in this work, DPBTPA and 2BPE-TPA (see Figure S10): in each case lowest fluorescence is obtained for the (E/Z) mixture, while pure (Z) and (E) exhibit three to five times higher luminescence efficiency. In every case the highest luminescence efficiency is obtained with the pure (E) isomer.

Aggregation threshold, which we define as the minimal $f_{w}$ of water required to initiate nucleation of the nanoprecipitation process, constitutes another important difference in the response of (E) and (Z) isomers towards water-induced aggregation. Evolution of the quantum yield of separated isomers indicates that (E) isomers systematically precipitate at lower $f_{w}$ than (Z). This discrepancy might account for the decreased quantum yield in nanoprecipitates of the $(\mathrm{E} / \mathrm{Z})$ isomer mixtures: those involve a quaternary system with water, THF and the two isomers, which differ in their sensitivity of nanoprecipitation to solvent mixture composition. This may affect the co-precipitation dynamics, leading in return to less define crystallization domains, with detrimental influence on the precipitates' luminescence efficiencies and reproducibility.

Such dependence of the solid state/nanoaggregates structures on the stereoisomeric composition has been already depicted in the past: in all cases different behaviours between (E) and $(\mathrm{Z})$ isomers regarding their spectroscopic (luminescence, ${ }^{40,41}$ mechanochromism ${ }^{42} \ldots$.) or supramolecular (self-assembly, ${ }^{43}$ crystallisation ${ }^{44} \ldots$ ) properties were shown to result from differences in their solid state intermolecular interactions. This phenomenon was sometimes referred to as the crystallization-induced emission enhancement (CIEE). ${ }^{45}$

It is likely that such a process is also responsible for the observed discrepancies in the present study, which we will study in details in the following sections of this article.
Lifetime measurements were finally performed on TPETPA ((Z) and (E) forms, (E/Z) mixture) in THF solution and in THF/water mixture with $\mathrm{f}_{\mathrm{w}}$ of $90 \%$. For chromophores in solution, the low fluorescence intensity did not provide reliable measurements (signal virtually undistinguishable from the prompt). In contrast, nanoprecipitates exhibit luminescence decays that could be fitted with good accuracy with monoexponential trend (Table 2 and S11). The (E)-TPE-TPA with the highest quantum efficiency has a lifetime significantly shorter than the (Z)-TPE-TPA isomer (1.73 vs $2.44 \mathrm{~ns}$ ). This suggests that the variations in luminescence efficiency result in difference in radiative rather than non-radiative parameters between these two isomers. Calculation of the radiative and non-radiative decay rates $\mathrm{k}_{\mathrm{r}}$ and $\mathrm{k}_{\mathrm{nr}}$ (using the relations $\mathrm{k}_{\mathrm{r}}=\Phi_{\mathrm{f}} / \mathrm{T}_{\mathrm{f}}, \mathrm{k}_{\mathrm{nr}}=$ $1 / \mathrm{T}_{\mathrm{f}}-\mathrm{k}_{\mathrm{r}}$ ) comforted this interpretation : while $\mathrm{k}_{\mathrm{nr}}$ values fall within the same range (and is even slightly reduced) between (E)-TPE-TPA and (Z)-TPE-TPA, $k_{r}$ values drop from 0.356 to $0.236 \mathrm{~ns}^{-1}$, respectively.

\begin{tabular}{|c|c|c|c|}
\hline & $\begin{array}{c}\text { (E/Z)-TPE- } \\
\text { TPA }\end{array}$ & $\begin{array}{c}\text { (Z)-TPE- } \\
\text { TPA }\end{array}$ & $\begin{array}{c}\text { (E)-TPE- } \\
\text { TPA }\end{array}$ \\
\hline $\mathbf{T}_{\mathbf{f}}$ & 1.81 & 2.44 & 1.73 \\
\hline$\chi^{\mathbf{2}}$ & 0.998 & 0.997 & 0.999 \\
\hline $\mathbf{k}_{\mathbf{r}}\left(\mathbf{n s}^{-1}\right)$ & 0.123 & 0.236 & 0.356 \\
\hline $\mathbf{k}_{\mathbf{n r}}\left(\mathbf{n s}^{-1}\right)$ & 0.429 & 0.174 & 0.222 \\
\hline
\end{tabular}

Table 2. Different fluorescence lifetimes $\left(\lambda_{\mathrm{ex}}=360 \mathrm{~nm}\right.$ and $\lambda_{\mathrm{em}}=530 \mathrm{~nm}$ ) obtained by multi-exponential fitting of mixed isomers, pure (Z) and (E) isomers of TPE-TPA in water/THF mixtures $\left(f_{w}=90 \%\right)$ and their correlation coefficient $\chi^{2}$.

Again, computational chemistry helped us rationalizing this trend. As mentioned before, calculations clearly show that the oscillator strength is strongly dependent on the torsional angle around the central double bond, with an oscillator strength that steadily decreases upon increasing the value of the dihedral angle: these torsional phenomena are at the basis of the relaxation process of the excited state; relaxed forms of the chromophore are essentially nonemissive, which explain the almost entire quenching of luminescence for solubilized chromophores. Conversely, at the solid state, any constraint to relaxation and thus any stabilization of the chromophore in a flatter conformation is expected to favour radiative deexcitation of the chromophore. As a matter of fact, for the (E) intermediate the oscillator strength for a flat double bond $\left(0^{\circ}\right.$ of dihedral angle) is 2.3 a.u. and becomes 1.7 a.u. for $15^{\circ}$ of distortion, illustrating that even small deviation from planarity can contribute in reducing radiative kinetics and, thereby, luminescence efficiency.

For nanoaggregates, structures of higher crystallinity (as in the case of (E)-TPE-TPA, see next section) and/or denser packing parameters offer a smaller free volume to allow effective relaxation and lead to a particularly marked AIE, 
characterized by a stronger emission intensity and reduced emission lifetime (Table 2), as observed here for (E)-TPETPA. Interestingly, this hypothesis also accounts for the aforementioned blue shift of the emission in the aggregated state, as a consequence of a frustrated reorganization process.

The trend is even more pronounced with (E/Z)-TPE-TPA where $\mathrm{kr}_{\mathrm{r}}$ is further reduced to $0.123 \mathrm{~ns}^{-1}$, indicative of an even more loosely packed aggregated state. However, compared with (E)-TPE-TPA and (Z)-TPE-TPA, it is also clear that nonradiative processes are much favoured in (E/Z)-TPE-TPA, with $\mathrm{k}_{\mathrm{nr}}$ values being on average doubled $\left(0,429 \mathrm{~ns}^{-1}\right.$ vs 0.22 and $0.174 \mathrm{~ns}^{-1}$, respectively). This indicates that, besides torsional relaxation processes around the central double bond, other more classical nonradiative phenomena linked to possible intermolecular interactions, vibrational phenomena (such as rotation of peripheral phenyl groups) or interactions with solvent molecules also participate in the strong decrease of the fluorescence QY observed in the latter case.

\section{Characterization of the aggregates}

Spectroscopic data seemingly indicate strong discrepancies in the precipitation features of stereopure fluorophore and (E/Z) mixture. To further investigate this point, characteristic dimensions and morphologies of the resulting nanoprecipitates were then investigated by means of dynamic light scattering (DLS) and field-emission scanning electron microscope (SEM). In the following of this study, a specific focus was made on TPE-TPA which appeared as the most suitable candidate for applications as a two-photon AIE emitter.

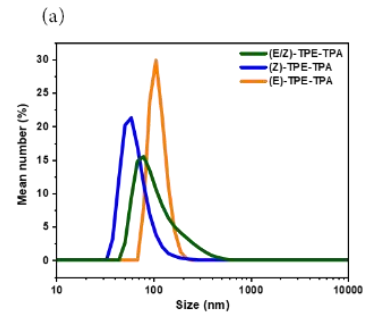

(c)

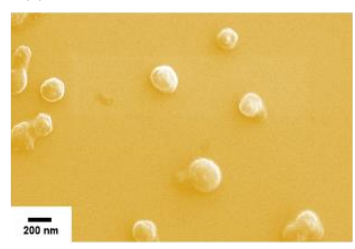

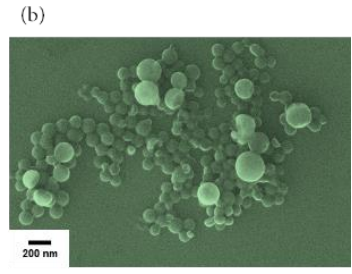

(d)

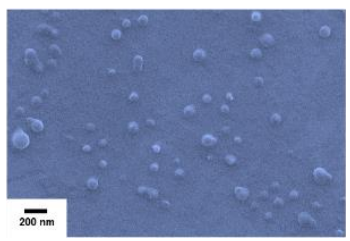

Figure 5. (a) DLS measurement of samples of nanoparticles of TPE-TPA of mixed isomers, pure (Z) and (E) isomers in water/THF mixtures $\left(f_{w}=90 \%\right)(b)$ Mixed isomers (green colourized) (c) (E) isomer (yellow colourized) and (d) (Z) isomer (blue colourized) SEM images of TPE-TPA nanoparticles in water/THF mixtures $\left(f_{w}=90 \%\right)$.

Nanoaggregates formed with our different chromophores' composition in THF/water media at $\mathrm{f}_{\mathrm{w}}$ of $90 \%$ were first analysed by DLS measurements (Figure $5 \mathrm{a}$ ). In the case of
(E/Z)-TPE-TPA, poorly-controlled aggregates were obtained, with an average diameter of $260 \mathrm{~nm}$. In comparison (Z) and (E) isomers self-assembled into NPs with a lower polydispersity, resulting in smaller average NP diameter of $70 \mathrm{~nm}$ and $120 \mathrm{~nm}$ respectively.

These DLS analyses thus confirm that the dynamic of organisation in aggregate, and thus the regularity of the obtained nano-objects, is dependent on the stereopurity of chromophore.

The formation of nanoparticles for these luminogens was confirmed by SEM (Figures 5b-d). Spherical nanoparticles are observed and average sizes are in good agreement with the DLS results for each compound. Furthermore, while the (E) and (Z) isomers result in relatively monodisperse populations of particles, significantly larger for the (E) isomer, the isomer mixture yields to a mixed population of small $(<100 \mathrm{~nm})$ and big $(>200 \mathrm{~nm})$ particles, witnessing a less regular assembly process. In spite of the absence of surfactant in their formulation, all suspensions displayed excellent colloidal stability. ${ }^{46}$

Powder X-ray diffraction (XRD) was used to estimate the crystallinity of chromophore's assembly within the nanoprecipitates. XRD profile of the mix of isomers of TPETPA, as monitored directly after freeze-drying of nanoprecipitates samples appeared weak and broad, characteristic of a dominant amorphous phase.

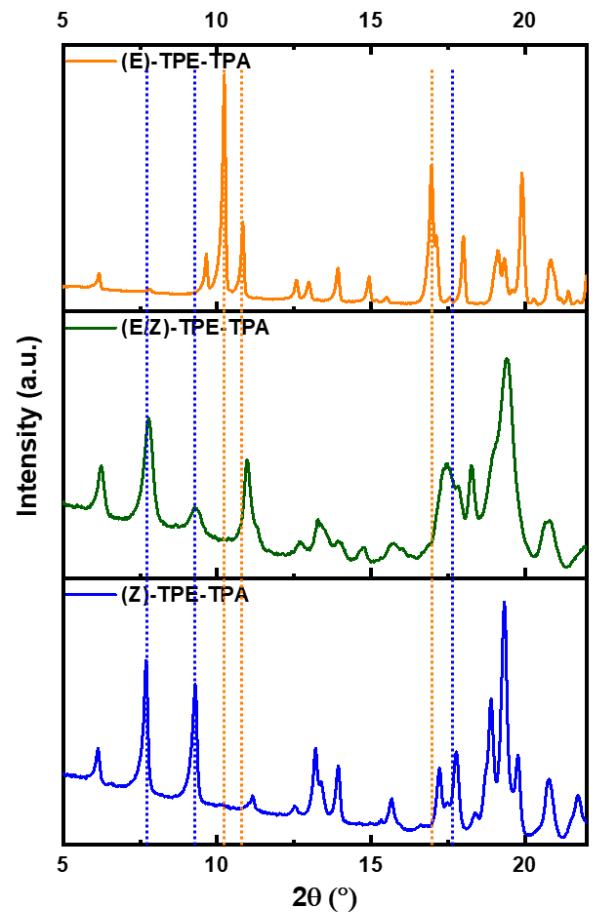

Figure 6. Powder XRD patterns of crystalline (E/Z) isomers (green line), (E) isomer (yellow line) and (Z) isomer (blue line) of TPE-TPA, dotted lines are a visual guide to underline the presence/absence of characteristic peaks from the (E) (yellow dotted) and (Z) (blue dotted) isomers in the mixture. 
Previous studies dealing with similar arrangement of nanoprecipitated TPE derivatives reported similar behaviour for nanoparticles as isolated after grinding, presumably because of detrimental influence of the grinding process on crystallinity. ${ }^{47,48}$ In these cases, crystallinity could however be restored upon simple fuming of the crude material with solvent vapours.

A similar strategy was therefore used on our samples. After submitting the isomer mixtures and stereopure compounds to DCM vapour, sharp and intense peaks appeared on their XRD pattern, typical of nanocrystalline structure (Figure 6). Examination of the XRD profiles allowed us to draw relevant conclusions regarding their respective supramolecular arrangement. First, diffractograms of the pure (Z) and (E) isomers present thinner and better resolved peaks than the mixture, indicative of a higher degree of crystallinity. This observation is consistent with our hypothesis of a CIEE mechanisms at the origin of the improved AIE properties of the pure stereoisomers compared to the (E/Z) mixture. Second, while the overall pattern of the $(\mathrm{Z})$ isomer and of the mixture present some strong similarities (blue dotted lines), the pattern of the (E) isomers appeared very different, showing peaks that were completely absent in the diffractogram of the mixture (yellow dotted line).

This indicates that the molecular arrangement of pure (E) isomer really stands out among the series, adopting a unique crystalline structure: it explains why this stereoconfiguration provides the best efficiency in terms of aggregation induced enhancement of luminescence efficiency, and the lowest aggregation threshold relative to $f_{w}$.

Although less classically employed than XRD powder, solidstate NMR spectroscopy under magic angle spinning (MAS) is also a powerful technique to probe atomic-scale structures and local order in powdered organic solids 49,50 . Indeed chemical shieldings are related to both molecular structure and packing. In parallel, any change in the linebroadening is informative about crystallinity and local order. Mainly, while the obtention of a XRD diffractogram of the three samples required preliminary fuming with vapor solvent prior to recording, solid-state NMR experiments can be carried out on the pristine samples as obtained after simple freeze drying of the nanoprecipitates, thus potentially conveying a more faithful picture of the molecular arrangement within the initial suspension. Solidstate NMR spectroscopy was therefore applied to complement the XRD study depicted above and refine our understanding of the molecular arrangement within the three types of nanoprecipitates (Z), (E), and (E/Z) of TPETPA. As descibed in the following, the analysis of the NMR spectra of the three powdered samples (Figure 7) strengthens the conclusions drawn from the XRD study.

First, while the carbon-13 NMR spectra of the (Z) and (E) forms were similar in solution, relatively marked differences appeared in the solid state. For example, a single resonnance is observed at 156 ppm for the phenyl carbon with methoxy group (B accoring labeling in Figure S5) of the (E) form while two peaks are present for the (Z) form. This reflects substantial differences in the crystal packing (e.g. two molecules per unit cell in the case of the $(Z)$ form, changes in the molecular geometries or presence of various polymorphs; see S5 for the complete attribution of the ${ }^{13} \mathrm{C}$ spectra of TPE-TPA).

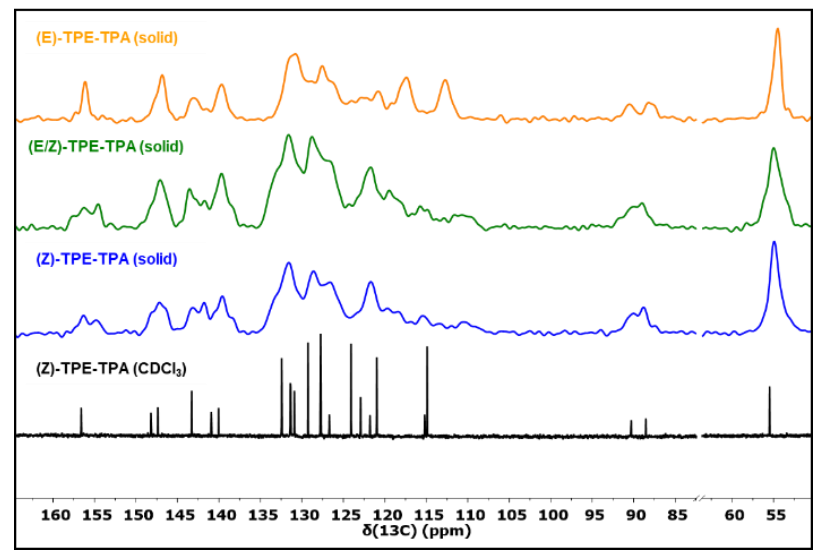

Figure 7. Solid-state MAS ${ }^{13} \mathrm{C}-\mathrm{NMR}$ cross-polarization (CP) NMR spectra of TPE-TPA (E) isomer (yellow), mixture of isomers (green) and (Z) isomer (blue). Spectra were recorded at $18.8 \mathrm{~T}(800 \mathrm{MHz}$ proton frequency) in $25 \mathrm{k}$ scans with a recycle delay of $1 \mathrm{~s}$, a CP contact time of $2 \mathrm{~ms}$ and at $20 \mathrm{kHz}$ MAS frequency in a $3.2 \mathrm{~mm}$ zirconium-oxide rotor. ${ }^{13} \mathrm{C}$ chemical shifts were referenced to the $\mathrm{CH}_{2}$ resonance of adamantane observed at $37.8 \mathrm{ppm}$. The solution NMR spectrum of (Z) isomer of TPE-TPA inserted for comparison (black).

Second, the inspection of the full widths at half maximum (FWHM) of the singlet corresponding to the methoxy (55.6 ppm in solution) constitutes a good standpoint for comparing the crystallinity of the three samples: a FWHM of $410 \mathrm{~Hz}$ is found for the mixture, significantly larger than the $280 \mathrm{~Hz}$ found for the (Z) isomer and $230 \mathrm{~Hz}$ for the (E) isomer, witnessing a higher crystallinity of the stereopure suspensions. A more detailed comparison of the peak patterns in the aromatic region reveals other interesting features: as already observed for the XRD difractograms, the NMR spectrum of the (E/Z) mixture does not correspond to the simple superimposition of the individual spectra of separated (E) and (Z) phases. The overall spectral signature is similar to that of the $(\mathrm{Z})$ isomer: this is especially noticeable in the $155-160 \mathrm{ppm}, 110-120 \mathrm{ppm}$ (peripheral phenyl rings) and 85-90 ppm (acetylene bond) regions, where the (E) form unlike the mixture and the (Z) form, displays relatively narrow and well-defined signals. All these results are in line with XRD powder patterns. They confirm that the difference in crystallinity between the isomers and the mixture is strong, and relate to interchromophoric interaction involving all parts of the chromophore that are very much influenced by the stereoconfiguration of the double bond. Again, the (E) isomer clearly stands apart, with defined and distinct sets 
of resonances, witnessing an improved degree of crystallinity and a different packing.

\section{Two-photon absorption measurements}

In view of future use of the nanosuspensions for 2PFM imaging we investigated their two-photon absorption properties. First, two-photon fluorescence excitation (TPFE) spectra of both isomers of TPE-TPA were recorded in THF solution in the 690-890 $\mathrm{nm}$ range, with a femtosecond pulsed laser source using the methodology depicted in S1 (Figure 8a). These TPFE spectra were compared to those of mixed and stereopure TPE-TPA in aggregated conditions ( $f_{w}=90 \%$, Figure $8 b$ ).
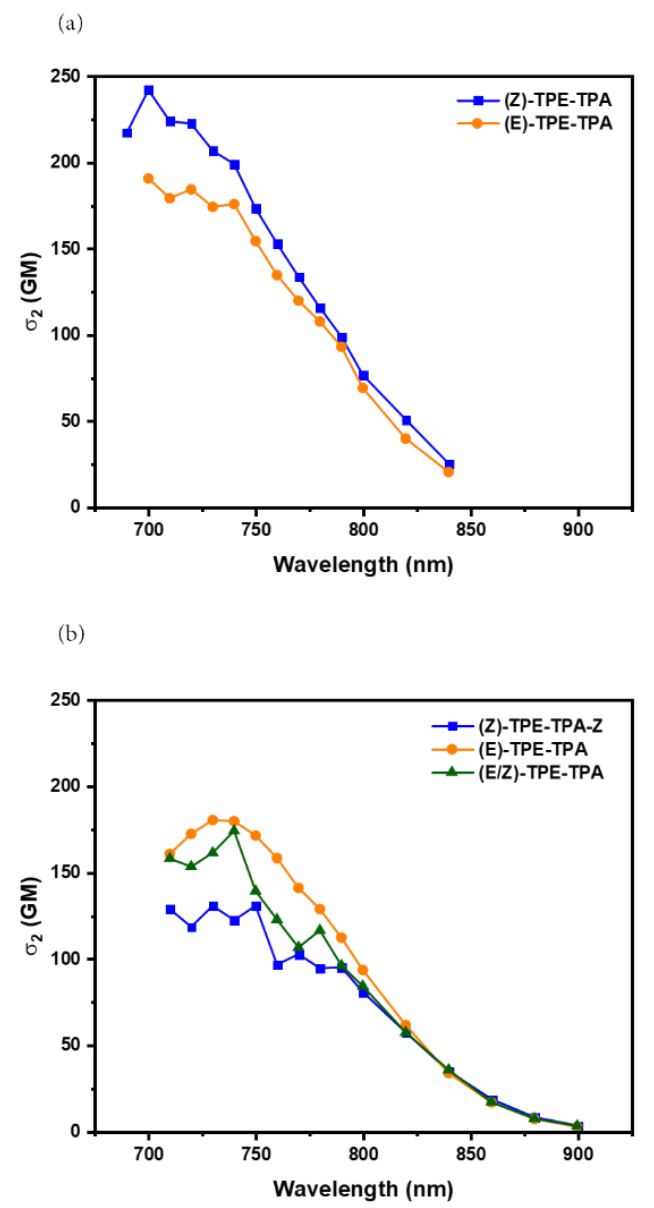

Figure 8. TPFE spectra of TPE-TPA isomers (a) in THF solution and $(b)$ in aggregated state $\left(f_{w}=90 \%\right)$.

Global profiles of TPE-TPA spectra are quite similar for solution or aggregates. For all compounds, the maximum 2PA intensities lies in a wavelength range of 720-730 nm, which corresponds to twice the maximal absorption wavelength of the $(\mathrm{Z})$ isomer in THF (361 nm), in good agreement with our attribution of this transition to a $\mathrm{S}_{0} \rightarrow \mathrm{S}_{2}$ transition (which in the case of (E), is two-photon allowed but one-photon forbidden, while allowed in both cases for $\mathrm{Z}$ isomer). Two-photon absorption cross sections are in the same 175-200 GM range in average for both solutions and aggregates (reported per chromophore molecule, for consistency) of the (E) isomer, while $\sigma_{2 \mathrm{PA}}$ seems to be divided by a factor $\mathrm{ca} 2$ for the (Z) isomer when going from THF solution (250 GM) to suspension (125 GM). This last observation should however be balanced, as evaluations of $\sigma_{2 \mathrm{PA}}$ in solution are biased by the small values in luminescence quantum yields of the compound in THF and the large relative errors associated. Measurements in the solid state are however much more reliable, and it can be concluded that the two-photon absorption cross section of the (E) isomer in suspension (180 GM) is significantly higher than that of the $(\mathrm{Z})(125 \mathrm{GM})$, while the $(\mathrm{E} / \mathrm{Z})$ isomer mixture suspension presents an intermediate value in the investigated range.

In all cases, these cross sections values may be considered low in regard with the size of the $\pi$-conjugated system, but can be explained by the marked distortions of the substituents around the central double bound (apparent in the computed ground state geometries of both molecules), which is also responsible for the relatively high energy and decrease in oscillator strength of the CT transition. Similarly, the higher value in 2PA cross-section in the case of the (E) isomer can be interpreted by a better conjugation within the molecule.

However, these values are sufficient to make individual nanoparticles extremely efficient two-photon emitters, considering the number and density of chromophores (with individual brightness $\sigma_{2 \mathrm{PA}}$. $\Phi_{\mathrm{f}}$ up to $c a 110 \mathrm{GM}$, for (E)-TPETPA) contained in each nanoparticle which confirms the potential of the newly designed TPE-TPA chromophore as a two-photon solid state emitter for bioimaging applications.

\section{Applications in one- and two-photon fluorescence microscopies}

As stated in previous paragraphs, nanoprecipitation of the stereopure version of TPE-TPA afforded spherical, weakly dispersed and colloidally stable organic nanoparticles, in spite of the absence of surfactant in the formulation. This observation prompted us to involve the as-prepared nanoparticles of (E)-TPE-TPA dispersed in water and supplemented with antibiotics, in a set of preliminary bioimaging experiments.

The cytotoxic effect of (E)-TPE-TPA on human breast cancer cell line (MCF-7) was first evaluated in a concentration range from 5 to $50 \mu \mathrm{g} \mathrm{mL} \mathrm{m}^{-1}$. As shown in Figure $9 a$, cell viability remained relatively high, $69 \pm 2 \%$ at $50 \mu \mathrm{g} \mathrm{mL}^{-1}$ of (E)-TPE-TPA. Importantly, the cell death was totally due to the vehicle (water supplemented with antibiotics) as demonstrated by the merge of both curves (control and (E)-TPE-TPA). Thus, we could state that, in the conditions of this study, (E)-TPE-TPA did not induce any cytotoxic effect. Then, cellular uptake and imaging potential of (E)-TPE-TPA in MCF-7 cells were studied using one- and two-photon excitation (Figure 9b). 

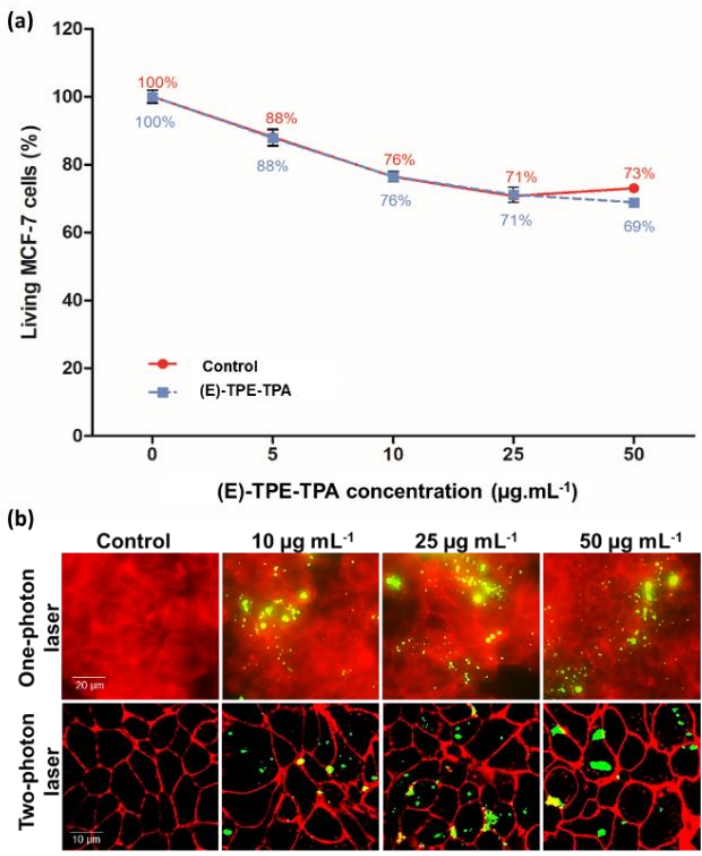

Figure 9. In vitro studies in MCF-7 breast cancer cells (a) Cytotoxicity study in cells treated with increasing concentrations of (E)-TPE-TPA from 5 to $50 \mu \mathrm{g} \mathrm{mL} \mathrm{m}^{-1}$ or equivalent volumes of vehicle for 3 days. Data are presented as (mean \pm SEM) of two independent experiments realized in triplicate. (b) Fluorescent microscopy imaging of living cells after $24 \mathrm{~h}$ of incubation with or without (Control) different concentrations of (E)-TPE-TPA and excited at 340$380 \mathrm{~nm}$ (one-photon excitation) or at $750 \mathrm{~nm}$ (two-photon excitation). Cell membranes appear in red and (E)-TPE-TPA appears as green bright dots.

This figure shows the accumulation of (E)-TPE-TPA inside the cells as bright and well defined spots, confirming the interest of the reported nanomaterial for imaging using one- and two-photon excitation.

(a)
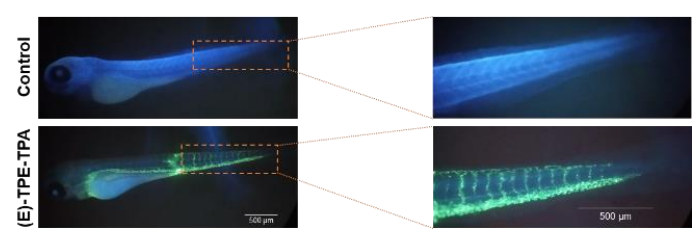

(b)

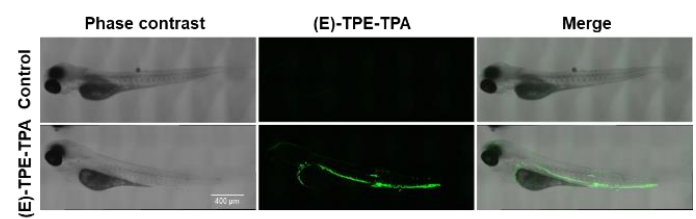

Figure 10. In vivo imaging potential assessment of (E)-TPETPA in Casper zebrafish embryos at 72 hpf using (a) onephoton excitation at $340-380 \mathrm{~nm}$. The whole embryos and the magnification were performed using objectives $4 \mathrm{x}$ and $10 \mathrm{x}$, respectively, (b) two-photon excitation at $750 \mathrm{~nm}$ using tile scan imaging, 10x objective. (E)-TPE-TPA appears as green bright dots.
Accordingly, transparent Casper zebrafish embryos at 72hour post-fertilization (hpf) were injected with (E)-TPETPA via the caudal cardinal vein. Imaging under one- and two-photon excitation was performed (Figure 10). Results showed the distribution of (E)-TPE-TPA in embryos vascular system, especially in the tail region where the dorsal longitudinal anastomotic vessel, intersegmental vessels, dorsal aorta and caudal cardinal vein were strongly stained with green fluorescence (Figure 10a). Additionally, (E)-TPE-TPA offered also the possibility to be detected in vivo under two-photon excitation as shown in Figure $10 \mathrm{~b}$.

\section{CONCLUSIONS}

In this paper, a synthetic methodology was introduced to elaborate various olefinic 2PA-AIEgens. HPLC on chiral support afforded highly effective separation of the (E) and (Z) isomers for each member of this family of chromophore, on hundreds of milligram scale, compatible with the preparation of significant amounts of fluorescent organic nanoparticles and a complete study of their properties.

Spectroscopic study of the subsequent separated diastereoisomers was achieved. Among the main conclusions of this study, we highlighted the link between crystallinity of nanoaggregate and fluorescence quantum yield. These results were supported by computational modelling of the chromophore, which suggests that the large reorganizations between the optimized ground and excited states of the chromophore account for the decrease in luminescence quantum yield. Thus, effective suppression of these molecular motions in the assembly of highest crystallinity results in higher luminescence efficiencies.

In the specific case of TPE-TPA, this link was further established using complementary structural investigations on the supramolecular arrangement of chromophores within the nanoparticles, involving XRD powder and solidstate NMR. Both techniques afforded similar conclusions, namely i/ Molecular packing of the stereopure compounds presents higher crystallinity and regularity than that of the stereoisomers mixture, at the origin of the differences in luminescence efficiency ii/ Looking more into details, supramolecular arrangements of the (E) isomers present a strong singularity compared to (Z) and (E/Z) mixture, which probably explain its superior aggregation properties and crystallisation induced increase emission efficiency.

Nanosuspensions obtained from the precipitation of both the $\mathrm{Z}$ and $\mathrm{E}$ isomers of TPE-TPA present a regular spherical structure, with a mean diameter ca $100 \mathrm{~nm}$ and an excellent colloidal stability. Although individual chromophore presents relatively modest $\sigma_{2 \mathrm{PA}}$, their assembly into large nanoparticles result in extremely bright nano-objects.

Consequently, they can be used directly, without any additive (surfactant), for cell and in vivo imaging by means of one- and two-photon fluorescence microscopy.

We hope that the molecular engineering and formulation principle introduced in this work will constitute valuable 
guidelines for future developments of stereo-controlled nanoparticles of TPE derivatives for multiphoton imaging applications.

\section{ASSOCIATED CONTENT}

Supporting Information. Materials and Methods, detailed experimental synthetic procedures for all new compounds, NMR characterizations and HPLC traces of all stereopure compounds, detailed spectroscopy for 2,3-Diphenyl-2-butene (DBP), 1,2-bis-(4-biphenyl)-1,2-diphenylethylene (2BPE) and stilbene (S) derivatives, TD-DFT results.

\section{AUTHOR INFORMATION}

\section{Corresponding Author}

*cyrille.monnereau@ens-lyon.fr.

\section{ACKNOWLEDGMENT}

The authors thank the Centre de RMN à Haut Champs, CRMN, FR CNRS 3050, for the access to their $1 \mathrm{GHz}$ NMR facilities. Dr. Frédéric Chaput and Caroline Arnoux are warmly acknowledged for their assistance in the acquisition of DRX patterns and SEM pictures, respectively. We greatly thank Pr. Julien Leclaire for inspiring discussions regarding stereoisomers separation by means of chiral chromatography. All authors would like to thank the imaging facility MRI and Mireille Rossel and Nicolas Cubedo for their technical assistance in Zebrafish experiments.

\section{REFERENCES}

(1) Yuan, W. Z.; Gong, Y.; Chen, S.; Shen, X. Y.; Lam, J. W. Y.; Lu, P.; Lu, Y.; Wang, Z.; Hu, R.; Xie, N.; Kwok, H. S.; Zhang, Y.; Sun, J. Z.; Tang, B. Z. Efficient Solid Emitters with Aggregation-Induced Emission and Intramolecular Charge Transfer Characteristics: Molecular Design, Synthesis, Photophysical Behaviors, and OLED Application. Chem. Mater. 2012, 24 (8), 1518-1528. https://doi.org/10.1021/cm300416y.

(2) Huang, J.; Sun, N.; Chen, P.; Tang, R.; Li, Q.; Ma, D.; Li, Z. Largely Blue-Shifted Emission through Minor Structural Modifications: Molecular Design, Synthesis, AggregationInduced Emission and Deep-Blue OLED Application. Chem. $\begin{array}{llll}\text { Commun. 2014, } 50 & \text { (17), 2136-2138. }\end{array}$ https://doi.org/10.1039/C3CC49313J.

(3) Guo, J.; Li, X.-L.; Nie, H.; Luo, W.; Gan, S.; Hu, S.; Hu, R.; Qin, A.; Zhao, Z.; Su, S.-J.; Tang, B. Z. Achieving HighPerformance Nondoped OLEDs with Extremely Small Efficiency Roll-Off by Combining Aggregation-Induced Emission and Thermally Activated Delayed Fluorescence. Adv. Funct. Mater. 2017, 27 (13), 1606458. https://doi.org/10.1002/adfm.201606458.

(4) Qian, J.; Tang, B. Z. AIE Luminogens for Bioimaging and Theranostics: From Organelles to Animals. Chem 2017, 3 (1),

56-91. https://doi.org/10.1016/j.chempr.2017.05.010.

(5) La, D. D.; Bhosale, S. V.; Jones, L. A.; Bhosale, S. V. Tetraphenylethylene-Based AIE-Active Probes for Sensing Applications. ACS Appl. Mater. Interfaces 2018, 10 (15),

12189-12216 https://doi.org/10.1021/acsami.7b12320.

(6) Würthner, F. Aggregation-Induced Emission (AIE): A Historical Perspective. Angew. Chem. Int. Ed. 2020, 59
(34), $14192-14196$ https://doi.org/10.1002/anie.202007525.

Luo, J.; Xie, Z.; Lam, J. W. Y.; Cheng, L.; Tang, B. Z.; Chen, H.; Qiu, C.; Kwok, H. S.; Zhan, X.; Liu, Y.; Zhu, D. AggregationInduced Emission of 1-Methyl-1,2,3,4,5Pentaphenylsilole. Chem. Commun. 2001, No. 18, 17401741. https://doi.org/10.1039/b105159h.

(8) Kokado, K.; Sada, K. Consideration of Molecular Structure in the Excited State to Design New Luminogens with Aggregation-Induced Emission. Angew. Chem. 2019, 131 (26), 8724-8731. https://doi.org/10.1002/ange.201814462.

Yang, Z.; Chi, Z.; Mao, Z.; Zhang, Y.; Liu, S.; Zhao, J.; Aldred, M. P.; Chi, Z. Recent Advances in Mechano-Responsive Luminescence of Tetraphenylethylene Derivatives with Aggregation-Induced Emission Properties. Mater. Chem. Front. 2018, 2 (5), 861-890. https://doi.org/10.1039/C8QM00062J.

(10) Porrès, L.; Mongin, O.; Katan, C.; Charlot, M.; Pons, T.; Mertz, J.; Blanchard-Desce, M. Enhanced Two-Photon Absorption with Novel Octupolar Propeller-Shaped Fluorophores Derived from Triphenylamine. Org. Lett. 2004, 6 (1), 47-50. https://doi.org/10.1021/ol036041s.

(11) Xu, B.; He, J.; Liu, Y.; Xu, B.; Zhu, Q.; Xie, M.; Zheng, Z.; Chi, Z.; Tian, W.; Jin, C.; Zhao, F.; Zhang, Y.; Xu, J. HighPerformance Two-Photon Absorption Luminophores: Large Action Cross Sections, Free from Fluorescence Quenching and Tunable Emission of Efficient Non-Doped Organic Light-Emitting Diodes. J. Mater. Chem. C 2014, 2 (17), 3416-3428. https://doi.org/10.1039/C3TC32052A. Qin, W.; Zhang, P.; Li, H.; Y. Lam, J. W.; Cai, Y.; K. Kwok, R. T.; Qian, J.; Zheng, W.; Zhong Tang, B. Ultrabright Red AIEgens for Two-Photon Vascular Imaging with High Resolution and Deep Penetration. Chem. Sci. 2018, 9 (10), 2705-2710. https://doi.org/10.1039/C7SC04820C.

(13) Monici, M. Cell and Tissue Autofluorescence Research and Diagnostic Applications. In Biotechnology Annual Review; Elsevier, 2005; Vol. 11, pp 227-256. https://doi.org/10.1016/S1387-2656(05)11007-2.

(14) Pansare, V. J.; Hejazi, S.; Faenza, W. J.; Prud'homme, R. K. Review of Long-Wavelength Optical and NIR Imaging Materials: Contrast Agents, Fluorophores, and Multifunctional Nano Carriers. Chem. Mater. 2012, 24 (5), 812-827. https://doi.org/10.1021/cm2028367.

(15) Pawlicki, M.; Collins, H. A.; Denning, R. G.; Anderson, H. L. Two-Photon Absorption and the Design of Two-Photon Dyes. Angew. Chem. Int. Ed. 2009, 48 (18), 3244-3266. https://doi.org/10.1002/anie.200805257.

(16) Rumi, M.; Ehrlich, J. E.; Heikal, A. A.; Perry, J. W.; Barlow, S.; $\mathrm{Hu}$, Z.; McCord-Maughon, D.; Parker, T. C.; Röckel, H.; Thayumanavan, S.; Marder, S. R.; Beljonne, D.; Brédas, J.-L. Structure-Property Relationships for Two-Photon Absorbing Chromophores: Bis-Donor Diphenylpolyene and Bis(Styryl)Benzene Derivatives. J. Am. Chem. Soc. 2000, $122 \quad$ (39), https://doi.org/10.1021/ja994497s.

(17) Lee, H. J.; Sohn, J.; Hwang, J.; Park, S. Y.; Choi, H.; Cha, M. Triphenylamine-Cored Bifunctional Organic Molecules for Two-Photon Absorption and Photorefraction. Chem. Mater. 2004, $16 \quad$ (3), 456-465. https://doi.org/10.1021/cm0343756.

(18) Gan, X.; Wang, Y.; Ge, X.; Li, W.; Zhang, X.; Zhu, W.; Zhou, H.; $\mathrm{Wu}$, J.; Tian, Y. Triphenylamine Isophorone Derivatives with Two Photon Absorption: Photo-Physical Property, DFT Study and Bio-Imaging. Dyes Pigments 2015, 120, 6573. https://doi.org/10.1016/j.dyepig.2015.04.007.

(19) Tykwinski, R. R.; Gubler, U.; Martin, R. E.; Diederich, F.; Bosshard, C.; Günter, P. Structure-Property Relationships 
in Third-Order Nonlinear Optical Chromophores. J. Phys. Chem. B 1998, 102 (23), 4451-4465. https://doi.org/10.1021/jp980829o.

(20) Fang, X.; Zhang, Y.-M.; Chang, K.; Liu, Z.; Su, X.; Chen, H.; Zhang, S. X.-A.; Liu, Y.; Wu, C. Facile Synthesis, Macroscopic Separation, E/Z Isomerization, and Distinct AIE Properties of Pure Stereoisomers of an Oxetane-Substituted Tetraphenylethene Luminogen. Chem. Mater. 2016, 28 (18), $6628-6636$ https://doi.org/10.1021/acs.chemmater.6b02746.

(21) Daik, R.; James Feast, W.; Batsanov, A. S.; Howard, J. A. K. Stereochemical Outcome of McMurry Coupling. New J. Chem. 1998, 22 (10), 1047-1049. https://doi.org/10.1039/a805208e.

(22) Jeong, K. S.; Kim, S. Y.; Shin, U.-S.; Kogej, M.; Hai, N. T. M.; Broekmann, P.; Jeong, N.; Kirchner, B.; Reiher, M.; Schalley, C. A. Synthesis of Chiral Self-Assembling Rhombs and Their Characterization in Solution, in the Gas Phase, and at the Liquid-Solid Interface. J. Am. Chem. Soc. 2005, 127 (50), 17672-17685. https://doi.org/10.1021/ja053781i.

(23) Qin, W.; Liu, J.; Chen, S.; Lam, J. W. Y.; Arseneault, M.; Yang, Z.; Zhao, Q.; Kwok, H. S.; Tang, B. Z. Crafting NPB with Tetraphenylethene: A Win-Win Strategy to Create Stable and Efficient Solid-State Emitters with AggregationInduced Emission Feature, High Hole-Transporting Property and Efficient Electroluminescence. J. Mater. Chem. C 2014, 2 (19), 3756-3761. https://doi.org/10.1039/C4TC00145A.

(24) Hundertmark, T.; Littke, A. F.; Buchwald, S. L.; Fu, G. C. $\mathrm{Pd}(\mathrm{PhCN})_{2} \mathrm{Cl}_{2} / \mathrm{P}(t-\mathrm{Bu})_{3}$ : A Versatile Catalyst for Sonogashira Reactions of Aryl Bromides at Room Temperature. Org. Lett. 2000, 2 (12), 1729-1731. https://doi.org/10.1021/ol0058947.

(25) Peluso, P.; Mamane, V.; Dallocchio, R.; Dessì, A.; Cossu, S. Noncovalent Interactions in High-Performance Liquid Chromatography Enantioseparations on PolysaccharideBased Chiral Selectors. J. Chromatogr. A 2020, 1623, 461202.

https://doi.org/10.1016/j.chroma.2020.461202.

(26) Armstrong, D. W.; DeMond, W.; Alak, A.; Hinze, W. L.; Riehl, T. E.; Bui, K. H. Liquid Chromatographic Separation of Diastereomers and Structural Isomers on CyclodextrinBonded Phases. Anal. Chem. 1985, 57 (1), 234-237. https://doi.org/10.1021/ac00279a054.

(27) Regalado, E. L.; Schafer, W.; McClain, R.; Welch, C. J. Chromatographic Resolution of Closely Related Species: Separation of Warfarin and Hydroxylated Isomers. J. Chromatogr. A 2013, 1314, 266-275. https://doi.org/10.1016/j.chroma.2013.07.092.

(28) Shibata, T.; Shinkura, S.; Ohnishi, A.; Ueda, K. Achiral Molecular Recognition of Aromatic Position Isomers by Polysaccharide-Based CSPs in Relation to Chiral Recognition. Molecules 2017, 22 (1), 38. https://doi.org/10.3390/molecules22010038.

(29) Shen, J.; Okamoto, Y. Efficient Separation of Enantiomers Using Stereoregular Chiral Polymers. Chem. Rev. 2016, 116 (3),

$1094-1138$

https://doi.org/10.1021/acs.chemrev.5b00317.

(30) Pirkle, W. H.; Welch, C. J.; Lamm, B. Design, Synthesis, and Evaluation of an Improved Enantioselective Naproxen Selector. J. Org. Chem. 1992, 57 (14), 3854-3860. https://doi.org/10.1021/jo00040a026.

(31) Mettra, B.; Le Bahers, T.; Monnereau, C.; Andraud, C. Photophysical Insights on the Influence of Excited States Reorganization Processes on the Visible and near InfraRed Luminescence of Two-Photon Quadrupolar Chromophores. Dyes Pigments 2018, 159, 352-366. https://doi.org/10.1016/j.dyepig.2018.06.023.
(32) Terenziani, F.; Painelli, A.; Katan, C.; Charlot, M.; Blanchard-Desce, M. Charge Instability in Quadrupolar Chromophores: Symmetry Breaking and Solvatochromism. J. Am. Chem. Soc. 2006, 128 (49), 15742-15755. https://doi.org/10.1021/ja064521j.

(33) Cannon, B. L.; Patten, L. K.; Kellis, D. L.; Davis, P. H.; Lee, J.; Graugnard, E.; Yurke, B.; Knowlton, W. B. Large Davydov Splitting and Strong Fluorescence Suppression: An Investigation of Exciton Delocalization in DNA-Templated Holliday Junction Dye Aggregates. J. Phys. Chem. A 2018 $122 \quad$ (8), 2086-2095. https://doi.org/10.1021/acs.jpca.7b12668.

(34) Hilborn, R. C. Einstein Coefficients, Cross Sections, f Values, Dipole Moments, and All That. Am. J. Phys. 1982, 50 (11), 982-986. https://doi.org/10.1119/1.12937.

(35) Shi, J.; Aguilar Suarez, L. E.; Yoon, S.-J.; Varghese, S.; Serpa, C.; Park, S. Y.; Lüer, L.; Roca-Sanjuán, D.; Milián-Medina, B.; Gierschner, J. Solid State Luminescence Enhancement in $\pi$-Conjugated Materials: Unraveling the Mechanism beyond the Framework of AIE/AIEE. J. Phys. Chem. C 2017, $121 \quad$ (41), 23166-23183. https://doi.org/10.1021/acs.jpcc.7b08060.

(36) An, B.-K.; Kwon, S.-K.; Jung, S.-D.; Park, S. Y. Enhanced Emission and Its Switching in Fluorescent Organic Nanoparticles. J. Am. Chem. Soc. 2002, 124 (48), 1441014415. https://doi.org/10.1021/ja0269082.

(37) Yang, J.-S.; Chiou, S.-Y.; Liau, K.-L. Fluorescence Enhancement of Trans-4-Aminostilbene by N-Phenyl Substitutions: The "Amino Conjugation Effect." J. Am. Chem. Soc. 2002, 124 (11), 2518-2527. https://doi.org/10.1021/ja016416+.

(38) Yang, J.-S.; Liau, K.-L.; Wang, C.-M.; Hwang, C.-Y. Substituent-Dependent Photoinduced Intramolecular Charge Transfer in N-Aryl-Substituted Trans-4Aminostilbenes. J. Am. Chem. Soc. 2004, 126 (39), 1232512335. https://doi.org/10.1021/ja047604d.

(39) Lanoë, P.-H.; Mettra, B.; Liao, Y. Y.; Calin, N.; D’Aléo, A.; Namikawa, T.; Kamada, K.; Fages, F.; Monnereau, C.; Andraud, C. Theoretical and Experimental Study on Boron $\beta$-Diketonate Complexes with Intense Two-PhotonInduced Fluorescence in Solution and in the Solid State. ChemPhysChem 2016, 17 (14), 2128-2136. https://doi.org/10.1002/cphc.201600178.

(40) Hu, R.; Lam, J. W. Y.; Liu, J.; Sung, H. H. Y.; Williams, I. D.; Yue, Z.; Wong, K. S.; Yuen, M. M. F.; Tang, B. Z. Hyperbranched Conjugated Poly(Tetraphenylethene): Synthesis, Aggregation-Induced Emission, Fluorescent Photopatterning, Optical Limiting and Explosive Detection. Polym. Chem. 2012, 3 (6), 1481-1489. https://doi.org/10.1039/C2PY20057K.

(41) Zhang, C.-J.; Feng, G.; Xu, S.; Zhu, Z.; Lu, X.; Wu, J.; Liu, B. Structure-Dependent Cis / Trans Isomerization of Tetraphenylethene Derivatives: Consequences for Aggregation-Induced Emission. Angew. Chem. Int. Ed. 2016, 55 (21), 6192-6196. https://doi.org/10.1002/anie.201600244.

(42) Wang, J.; Mei, J.; Hu, R.; Sun, J. Z.; Qin, A.; Tang, B. Z. Click Synthesis, Aggregation-Induced Emission, $E$ / $Z$ Isomerization, Self-Organization, and Multiple Chromisms of Pure Stereoisomers of a Tetraphenylethene-Cored Luminogen. J. Am. Chem. Soc. 2012, 134 (24), 9956-9966. https://doi.org/10.1021/ja208883h.

(43) Zhang, M.; Yin, X.; Tian, T.; Liang, Y.; Li, W.; Lan, Y.; Li, J.; Zhou, M.; Ju, Y.; Li, G. AIE-Induced Fluorescent Vesicles Containing Amphiphilic Binding Pockets and the FRET Triggered by Host-Guest Chemistry. Chem. Commun. 2015, $51 \quad$ (50), 10210-10213 https://doi.org/10.1039/C5CC02377G. 
(44) Xie, N.; Liu, Y.; Hu, R.; Leung, N. L. C.; Arseneault, M.; Tang, B. Z. Synthesis, Aggregation-Induced Emission, and Electroluminescence of Dibenzothiophene- and Dibenzofuran-Containing Tetraarylethenes. Isr. J. Chem. 2014, 54 (7), 958-966. https://doi.org/10.1002/ijch.201400058.

(45) Dong, Y.; Lam, J. W. Y.; Qin, A.; Li, Z.; Sun, J.; Sung, H. H.-Y.; Williams, I. D.; Tang, B. Z. Switching the Light Emission of (4-Biphenylyl)Phenyldibenzofulvene by Morphological Modulation: Crystallization-Induced Emission Enhancement. Chem Commun 2007, No. 1, 40-42. https://doi.org/10.1039/B613157C.

(46) SEM images were recorded over a year after initial preparation of the samples.

(47) Misra, R.; Jadhav, T.; Dhokale, B.; Mobin, S. M. Reversible Mechanochromism and Enhanced AIE in Tetraphenylethene Substituted Phenanthroimidazoles.
Chem. Commun. 2014, 50 (65), 9076-9078. https://doi.org/10.1039/C4CC02824D.

(48) Qi, Q.; Liu, Y.; Fang, X.; Zhang, Y.; Chen, P.; Wang, Y.; Yang, B.; Xu, B.; Tian, W.; Zhang, S. X.-A. AIE (AIEE) and Mechanofluorochromic Performances of TPEMethoxylates: Effects of Single Molecular Conformations. RSC Adv. 2013, 3 (21), 7996-8002. https://doi.org/10.1039/C3RA40734A.

(49) Harris, R. K. NMR Studies of Organic Polymorphs \& Solvates. Analyst 2006, 131 (3), 351-373. https://doi.org/10.1039/B516057J.

(50) Martineau, C.; Senker, J.; Taulelle, F. Chapter One - NMR Crystallography. In Annual Reports on NMR Spectroscopy; Webb, G. A., Ed.; Academic Press, 2014; Vol. 82, pp 1-57. https://doi.org/10.1016/B978-0-12-800184-4.00001-1. 